\title{
An investigation of the middle and late behavioural phenotypes of Mucopolysaccharidosis Type-III
}

\author{
Elaine M Cross ${ }^{1}$, Sheena Grant ${ }^{1}$, Simon Jones², Brian W Bigger ${ }^{3}$, James E Wraith`, Louise V Mahon', \\ Michelle Lomax ${ }^{1}$ and Dougal J Hare ${ }^{1 *}$
}

\begin{abstract}
Background: Mucopolysaccharidosis type-III (MPS III) is an autosomal recessive lysosomal storage disorder. It causes progressive physical and cognitive decline and has been linked to increased incidences of behavioural problems.

Methods: Data on the behaviour and adaptive skills of 20 children with MPS III and 25 children with intellectual disability (ID) (17 included in analysis) were gathered via parental report questionnaire. The frequencies of different types of behaviour displayed by children with MPS III and children with ID were compared across two age categories.

Results: The total frequency of challenging behaviours displayed by children aged 2-9 years with MPS III and ID was not significantly different. Behaviours associated with hyperactivity, orality, unusual body movements and inattention were seen significantly more frequently in 2-9 year olds with MPS III than in those with ID. Children aged 10-15 years with MPS III showed significantly fewer problem behaviours than a contrasting group with ID. The frequency of challenging behaviours displayed by children with MPS III and their adaptive skills was found to decrease with age.

Conclusions: Behaviours relating to hyperactivity, orality, unusual body movements and inattention are part of the behavioural phenotype of the middle phase of MPS III. The late phase of MPS III is associated with low rates of problem behaviour and loss of adaptive skills. Therefore, families with a child with MPS III may benefit from a different type of clinical service when the child is aged 2-9 years, than when aged 10-15 years.
\end{abstract}

Keywords: Sanfilippo syndrome, Mucopolysaccharidosis, MPS III, Behavioural phenotype

\section{Background}

Mucopolysaccharidosis type-III (MPS III (Sanfilippo syndrome)) is a recessively inherited lysosomal storage disorder and is the most prevalent of the seven mucopolysaccharide (MPS) disorders, occurring 0.28-4.1 in 100,000 live births [1]. MPS disorders are caused by deficiency in enzymes responsible for the degradation of glycosaminoglycans (GAGs) and subsequent GAG accumulation in various organs causes a multi-system disease [2]. MPS III has four subtypes A to D associated with a specific enzyme deficiency. All four enzymes, heparan $\mathrm{N}$-sulfatase, a- $\mathrm{N}$-actylglucosaminidase, acetyl-CoA: a-glycosaminide and $\mathrm{N}$-acetylglucosamine 6 -sulfatase (A to D, respectively), are associated with the breakdown

\footnotetext{
* Correspondence: dougal.hare@manchester.ac.uk

'Deceased

'Section for Clinical and Health Psychology, School of Psychological Sciences, University of Manchester, Zochonis Building, Brunswick Street, Manchester M13 9PL, UK

Full list of author information is available at the end of the article
}

of heparan sulphate [3]. The most prevalent type in the UK is type $A$; type $B$ is less common and types $C$ and $D$ rare [4].

MPS III causes severe neurological impairment and a gradual decline in functioning with a tri-phasic clinical course. The beginning phase (1-2 years) is characterised by developmental delay but normal stature and physical growth [5]. The middle phase (2-9 years) shows considerable variation and is characterised by behavioural problems and sleep disturbance. The late phase $(10+$ years $)$ is associated with skill loss, reduced behaviour problems, loss of motor skills, increased spasticity, seizures and swallowing difficulties [5]. Other symptoms include recurrent diarrhoea; ear, nose and throat infections; and visual impairment [6]. Age of death varies within and between subtypes with a median of 15.2 years for type A [7] and 34 years for type $\mathrm{C}[8]$.

A recent survey of care professionals and families investigating non-carcinomatous life-limiting conditions 
identified MPS disorders as the primary priority for further research, given the complex symptom profile, difficulties in managing symptoms and distress experienced by families $[9,10]$. Research into treatments is ongoing but inconclusive [11].

A recent systematic review of behaviour and development in MPS III [12] identified behaviour problems, including restlessness and hyperactivity, physical aggression, unusual affect (laughing/screaming/crying), 'tantrums' and orality $[5,7,8,13-20]$, as strongly associated with the middle phase, thence declining with age and loss of functions [8]. Sleep and circadian rhythm were found to be significantly different from matched controls in two studies $[5,21]$. Linguistic and motor development was 'relatively normal' for the 1st year with first signs and symptoms differing between subtypes, ranging from 2 years 3 months to 5 years. Age at onset of cognitive delay and rate of decline increased across types A to D respectively [13].

Research to date has been limited by inadequate measurement, control groups, statistical analyses and methodologies (e.g. case-note review). To address this, the present study used validated and syndrome-specific measures and a genetically distinct, ability-matched, control group to address the following research questions:

1: Do the frequencies of challenging behaviour differ significantly between children with MPS III and children with ID?

2: Are any types of challenging or adaptive behaviour observed significantly more frequently in children with MPS III than in children with ID?

\section{Methods}

\section{Recruitment}

\section{Children with MPS III}

This study was conducted alongside other studies investigating sleep, circadian rhythm and family functioning $[22,23]$ with recruitment through the MPS Society UK and a genetics department in the North West of England. Questionnaires were sent to 25 families with a child with MPS III with 20 returned.

\section{Children with intellectual disability (ID)}

Families of children with intellectual disability (ID) were recruited through national and local MENCAP and 30 local parent support agencies across the UK. Sixty-six questionnaire packs were sent out with 24 returned.

\section{Sample}

Children with MPS III were included in the study if they had a diagnosis of MPS III (any subtype) made via genetic/enzyme testing, were resident in the UK and their parents understood written English. People with MPS III were excluded if they had received gene or enzyme replacement therapy or a bone marrow transplant and if they were under 2 years of age. Children with ID were included if they had an intellectual disability, were aged 2-15 years, their parents understood written English and were resident in the UK and were excluded if they had an autistic spectrum condition but an IQ $>70$ and if they were under 2 years of age.

\section{Design}

Parents/carers (MPS III or ID) 'opted in' via telephone or email. Information and consent forms and questionnaires were sent via post. When possible, families were telephoned to collect missing data.

\section{Materials/measures}

Demographic Questionnaire-used to collection information on age, diagnosis, treatments received, deafness, blindness, epilepsy, medications and GP details.

Learning Disability Casemix Scale (LDCS) [24]— measures degree (mild/moderate/severe) of ID (A) and frequency and severity of challenging behaviour (C), based upon the widely used Wessex Behaviour Schedule [25].

Vineland Adaptive Behavior Scale, Second EditionParent/Carer Rating Form (VABS-II) [26]-measures current adaptive and maladaptive behaviour across 11 subdomains within 4 domains of communication, daily living skills, socialisation and motor skills. Each subdomain contains lists of adaptive skills and respondents rate if the child/adult can do this; 'Usually' $=2$, 'Sometimes/ Partially' $=1$ or 'Never' $=0$. The measure gives an overall adaptive behaviour score (Adaptive Behaviour Composite) as well as age equivalent scores and standard scores for each domain. Internal consistency reliability is moderate to high for domain scores $(a=0.71-0.95)$ and high for Adaptive Behaviour Composite score $(a=0.86-0.98)$ across all ages [26].

Aberrant Behaviour Checklist (ABC) [27]-measures severity of a child's behaviour in the last month, with each behaviour problem rated from 0 (not a problem at all) to 3 (the problem is severe in degree) across domains of irritability/agitation, crying/lethargy, social withdrawal/stereotypic behaviour, hyperactivity/noncompliance and inappropriate speech. Internal consistency is good across all domains $(a=0.86-0.95)$ [27-29].

Eyberg Child Behaviour Inventory (ECBI) [30,31]measures frequency and severity of current behavioural problems for children aged 2-17 years, with frequency of behaviours rated from 1 (never) to 7 (always) to give a behaviour 'intensity' score. Respondents state if each behaviour is a problem for them, and the number of problematic behaviours is summed to give a 'problem' score. The ECBI has high internal consistency for both problem $(a=0.94)$ and intensity $(a=0.95)$ domains [32]. It has been found to provide a homogenous measure of conduct problems when used via post [32]. 
Table 1 Participant demographics

\begin{tabular}{|c|c|c|c|c|}
\hline & & $\begin{array}{l}\text { 2-9-year age } \\
\text { group }\end{array}$ & $\begin{array}{l}\text { 10-15-year age } \\
\text { group }\end{array}$ & $\begin{array}{c}16+\text { year age } \\
\text { group }\end{array}$ \\
\hline \multirow[t]{7}{*}{ MPS III } & $N$ & 10 & 10 & 5 \\
\hline & Median age & 4.5 & 12.5 & 28 \\
\hline & $\begin{array}{l}\text { Youngest to } \\
\text { oldest }\end{array}$ & $2-9$ & $10-15$ & $16-32$ \\
\hline & Median ID score & $30(N=8)$ & 37.5 & 39 \\
\hline & (range) & $(26-36)$ & $(20-40)$ & $(31-41)$ \\
\hline & Gender & $\begin{array}{l}7 \text { male, } \\
3 \text { female }\end{array}$ & $\begin{array}{l}4 \text { male, } \\
6 \text { female }\end{array}$ & $\begin{array}{l}2 \text { male, } \\
3 \text { female }\end{array}$ \\
\hline & Genetic subtypes & $2 \times A, 7 \times B, C$ & $7 \times A, 3 \times B$ & $2 \times A, 2 \times B, C$ \\
\hline \multirow[t]{7}{*}{ ID } & $N$ & 10 & 7 & - \\
\hline & Median age & 4 & 12 & \\
\hline & $\begin{array}{l}\text { Youngest to } \\
\text { oldest }\end{array}$ & $2-8$ & $10-15$ & \\
\hline & Median ID score & 31.5 & 22 & \\
\hline & (range) & $(26-38)$ & $(17-32)$ & \\
\hline & Diagnosis & $\begin{array}{c}2 x A S D, 3 x D S \\
A S, C D\end{array}$ & $3 x A S D, A S, C D$ & \\
\hline & Gender & $\begin{array}{l}7 \text { male, } \\
3 \text { female }\end{array}$ & $\begin{array}{l}4 \text { male, } \\
3 \text { female }\end{array}$ & \\
\hline
\end{tabular}

ASD autism spectrum disorder, DS Down syndrome, AS Angelman syndrome, $C D$ chromosome deletion [unspecified].

Sanfilippo Behaviour Rating Scale (SBRS) [33]comprises three sections: communication, tantrums and behaviour. The scale is composed of past and present communication skills (Section I); frequency, duration and emotions expressed during tantrums (Section II); and frequency, onset and cessation of relevant motor, perceptual, social and emotional skills and behaviour (Section III). The SBRS is under development for use in MPS III treatment trials.

\section{Statistical analysis}

All data were anonymised, stored and analysed in accordance with the Data Protection Act (1998). Data were analysed using the Statistical Package for the Social Sciences (SPSS) versions 16.0 and 19.0. Children were divided into age groups associated with stages of the disorder: 2-9 years (middle phase) and 10-15 years (late phase), with poorly matched controls being excluded from the ID group.

Questionnaire scores were tested for normality using the Kolmogorov-Smirnov test and by examination of Q-Q and P-P probability plots (graphical representation and comparison of the data distribution). Although most scores were normally distributed, the sample size was small, and non-parametric statistics (Mann-Whitney U and Spearman rho) were used for all analyses with twotailed significance values. As the SBRS is a relatively new measure, Cronbach's $\alpha$ was calculated to test for reliability (internal consistency).

Total measure scores and domain scores were calculated according to the measure guidelines. The functioning of children with MPS III and ID was so low that the standardised scores and some age-equivalent scores on the VABS-II were not meaningful, and raw scores were therefore used for comparison as the groups were matched for age and ability. Raw scores were summed to give domain

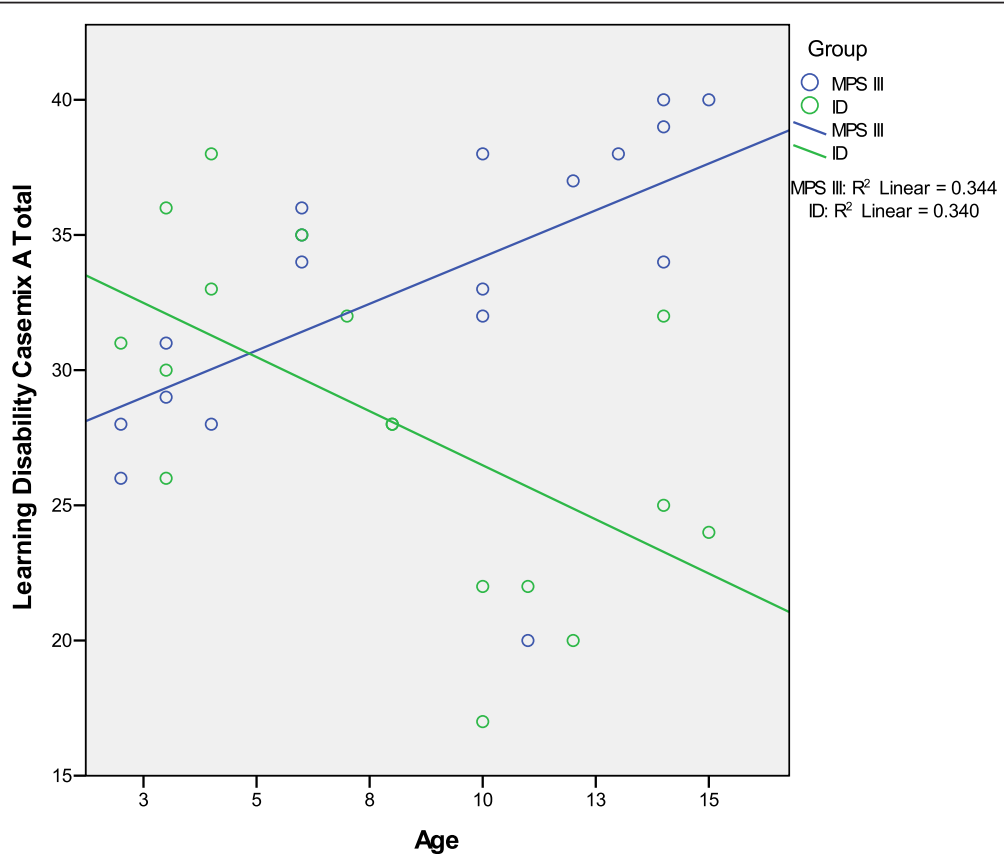

Figure 1 Graph showing the relationship between age and disability score. 


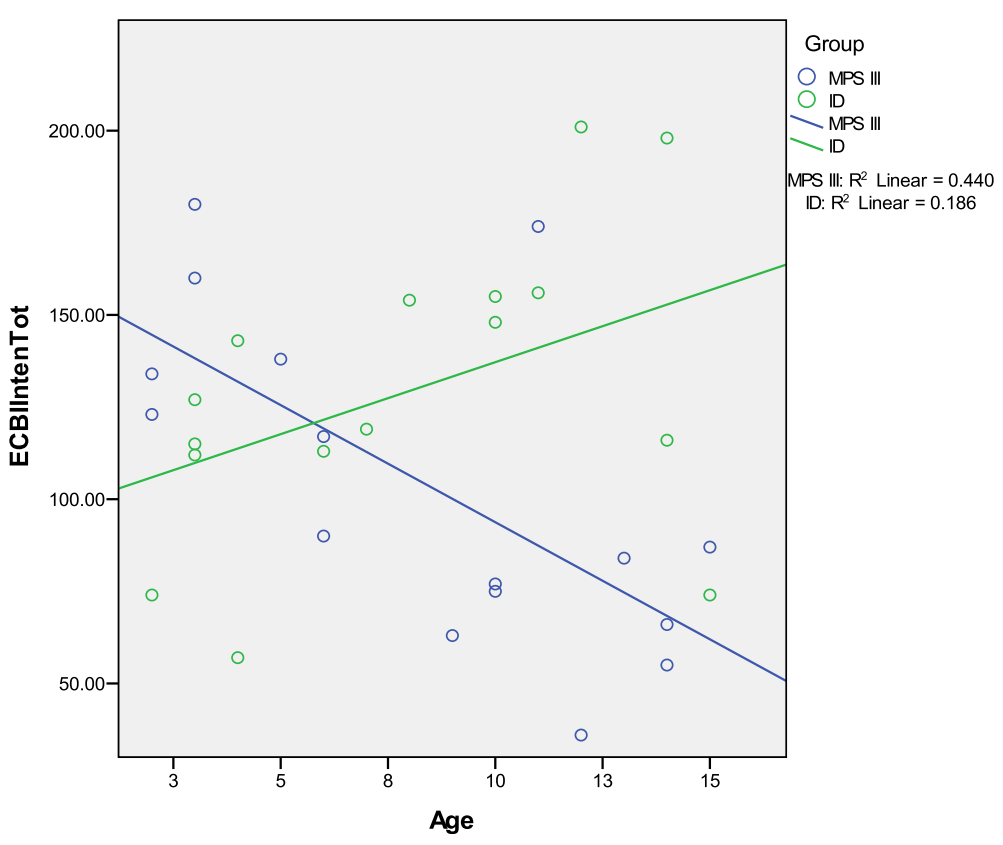

Figure 2 Graph of the relationship between ECBI Intensity score and age.

raw scores, and these were summed to give a measure raw score. All measure scores, domain scores and subdomain scores were compared between children with MPS III and children with ID. Bonferroni adjustments were not used as these would have given too conservative a cut-off for significance, increasing the chance of Type II errors [34]. Effect sizes $(r=Z / \sqrt{ } n$ [35]) were computed for all significant findings taking $p<0.05$ used as cut-off for significance in all comparisons.

\section{Ethical approval}

This study was approved by NHS North West Research Ethics Committee, University of Manchester School of
Psychological Sciences Ethics Committee and Central Manchester Foundation Trust Research and Design department.

\section{Results}

Data for 20 children with MPS III $(N=10$ aged $2-9$ years; $N=10$ aged $10-15$ years $)$ and 25 children with ID $(N=15$ aged 2-9 years; $N=10$ aged $10-15$ years) were collected. In the 2-9-year age group, all children with MPS III had severe ID, and therefore, only children receiving a score indicative of severe ID were included in the control group ( $N=10$ remained). In the 10-15-year age group, all the children with MPS III had severe or moderate ID and

Table 2 VABS-II subdomain scores (2-9 year olds)

\begin{tabular}{|c|c|c|c|c|c|c|}
\hline Domain & Subdomain & $\begin{array}{c}\text { MPS III raw score median } \\
(N, \text { range })\end{array}$ & $\begin{array}{l}\text { MPS III age equivalent } \\
\text { (years: months) }\end{array}$ & $\begin{array}{l}\text { ID raw score median } \\
(N, \text { range })\end{array}$ & $\begin{array}{l}\text { ID age equivalent } \\
\text { (years: months) }\end{array}$ & $p$ value \\
\hline \multirow[t]{3}{*}{ Communication } & Receptive & $11(9,5-16)$ & $1: 0$ & $12.5(10,6-23)$ & $1: 1$ & 0.512 \\
\hline & Expressive & $17(9,9-42)$ & $0: 10$ & $13(10,8-22)$ & $0: 8$ & 0.164 \\
\hline & Written & $0(8,0-3)$ & $\leq 1: 10$ & $0(9,0-14)$ & $\leq 1: 10$ & 0.301 \\
\hline \multirow[t]{3}{*}{ Daily living skills } & Personal & $15(9,7-26)$ & 1:5 & $12(10,4-34)$ & $1: 2$ & 0.870 \\
\hline & Domestic & $1(9,0-10)$ & 0:10 & $0(10,0-8)$ & $\leq 0: 7$ & 0.435 \\
\hline & Community & $3(9,0-7)$ & $0: 11$ & $3(10,0-8)$ & $0: 11$ & 0.901 \\
\hline \multirow[t]{3}{*}{ Socialisation } & Interpersonal relationships & $23(8,15-36)$ & $0: 9$ & $22.5(10,14-43)$ & $0: 8$ & 0.447 \\
\hline & Play and leisure & $13.5(8,0-26)$ & $1: 2$ & $6(9,3-22)$ & $0: 7$ & 0.311 \\
\hline & Coping skills & $5(9,0-18)$ & $1: 1$ & $5.5(0,0-13)$ & $1: 1$ & 0.967 \\
\hline \multirow[t]{2}{*}{ Motor skills } & Gross & $59(7,46-62)$ & $2: 5$ & $42(10,12-58)$ & $1: 4$ & 0.013 \\
\hline & Fine & $30(7,14-37)$ & $2: 8$ & $23(9,9-28)$ & $2: 0$ & 0.050 \\
\hline
\end{tabular}


children with mild ID were excluded from the comparison group $(N=7)$ (Table 1$)$.

The SBRS current understanding, past understanding, orality, body movements, fearfulness, attention, selfcontrol/compliance and mood, anger and aggression domains had good internal reliability $(\alpha>0.7)$, the remaining domains having poor internal reliability $(\alpha<0.7)$.

As seen in Figure 1, there was an outlier in the MPS III group with a high level of skills aged 11 years. Subsequent analyses were conducted both with and without this outlier, but the latter are only reported if these differed from those conducted with the whole dataset. Skills increased with age for the ID group (green line) but decreased with age for the MPS III group (blue line), with LDCS A score being significantly correlated with age in the MPS III group $(r=0.728, p=0.01)$.

Frequency of challenging behaviour (ECBI Intensity score) and level of disability (LDCS A score) were negatively correlated in both the MPS III $(r=-0.676, p=0.008)$ and ID $(r=-0.573, p=0.02)$ groups, but this relationship was non-significant in the MPS III when the outlying case was omitted, which was most likely due to the lack of variability in the MPS group.

Figure 2 shows the relationship between the ECBI behaviour intensity score and age. For the MPS III group (blue line), the frequency of behavioural problems reduced with age, while for the ID group (green line) the frequency increases. Age and intensity score were significantly negatively correlated for children with MPS III $(r=-0.639, p=0.008)$, but this was non-significant when the outlier was removed.

\section{Middle phase (2-9-year-old group)}

In terms of adaptive skills measured by the VABS-II, MPS III group scores were significantly higher than ID scores for the gross motor skills subdomain only, with a large effect size $(U=13, z=-2.493, r=-0.605, p=0.013)$ (Tables 2 and 3).

In the MPS III group, the median ECB score in the MPS III group exceeded clinical cut-off (15); ABC hyperactivity scores were significantly higher with a large effect size $(U=13, z=-2.151, r=-0.522, p=0.031)$, and SBRS domain scores were significantly higher for orality ( $U=11, z=-2.78, r=-0.638, p=0.005)$, body movements $(U=14.5, z=-2.493, r=-0.572, p=0.013)$, interactions with objects ( $U=14.5, z=-2.493, r=-0.572 p=0.022)$ and attention ( $U=20, z=-2.054, r=-0.471 p=0.04)$ domains. Of the children with MPS III, 67\% reported some sleep problems and $33 \%$ reported severely disrupted sleep.

\section{Late phase (10-15 years group)}

Total VABS-II measure and domain scores were lower in the MPS III group with daily living skills being significantly so $(U=8.5, z=-2.261, r=-0.584, p=0.024)$ (Table 4$)$.
Table 3 Behaviour-related domain scores (2-9 age group)

\begin{tabular}{cccc}
\hline Measure/domain & MPS III & ID & $p$ value \\
\hline & $\begin{array}{c}\text { Median } \\
(N, \text { range })\end{array}$ & $\begin{array}{c}\text { Median } \\
(N, \text { range })\end{array}$
\end{tabular}

$\mathrm{ECBI}$

Intensity score

$128(8,63-180) \quad 115(9,57-154) \quad 0.336$

Problem score

$16(7,0-27)$

$11(9,1-20)$

0.761

$A B C$

Irritability

$8(7,3-31) \quad 11.5(10,1-22) \quad 0.494$

Lethargy

$10(7,0-29) \quad 9.5(10,1-29) \quad 0.732$

Stereotypy

Hyperactivity

Inappropriate speech

$A B C$ total score

SBRS

Current understanding

Past understanding

$4(7,0-12) \quad 0.5(10,0-14)$

0.577

$27(7,10-38) \quad 11(10,5-28) \quad 0.031$

$3(7,0-9) \quad 0(10,0-5) \quad 0.08$

$58(7,13-113) \quad 34(10,10-91) \quad 0.525$

Current expression

Past expression

Orality

Body movements

Interactions with objects

Activity and routines

Emotional function

Safety consciousness

Fearfulness

Social interaction

Eye contact

Emotional engagement

Comfort seeking

Attention

Self-control/compliance

$28(9,11-35) \quad 24.5(10,5-40) \quad 0.902$

$30(7,24-41) \quad 12.5(4,0-35) \quad 0.130$

$8(9,1-12) \quad 6.5(10,4-14) \quad 0.967$

$6(6,2-17) \quad 3(5,0-6) \quad 0.125$

$29(9,11-33) \quad 12.5(10,0-24) \quad 0.005$

$22(9,5-27) \quad 6.5(10,0-18) \quad 0.013$

$14(9,2-20) \quad 7(10,0-12) \quad 0.022$

$22(9,11-36) \quad 15.5(10,8-26) \quad 0.078$

$5(9,0-16) \quad 4(10,0-12) \quad 0.536$

$14(9,8-18) \quad 10.5(10,6-18) \quad 0.267$

$28(9,16-38) \quad 28(10,9-40) \quad 0.806$

$16(9,8-24) \quad 20(10,12-26) \quad 0.388$

$8(9,2-18) \quad 5(10,0-10) \quad 0.201$

$7(9,0-13) \quad 11.5(10,1-16) \quad 0.234$

$9(9,6-23) \quad 5.5(10,0-24) \quad 0.078$

$14(9,10-18) \quad 8.5(10,5-18) \quad 0.040$

$11(9,0-18) \quad 9.5(10,2-15) \quad 0.461$

Mood, anger and aggression $11(9,5-33) \quad 10(10,4-24) \quad 0.582$

Self-gratification

$0(9,0-7) \quad 0.5(10,0-11) \quad 0.649$

Significantly lower scores with large effect sizes were reported for written communication $(U=11, z=-2.042$, $r=-0.527, p=0.041)$, personal skills $(U=9.5, z=-2.143$, $r=-0.553, p=0.032)$, domestic skills $(U=3, z=-3.05$, $r=-0.788, p=0.002)$, community skills $(U=8.5, z=-2.288$, $r=-0.591, p=0.022)$ and coping skills $(U=9.5, z=-2.16$, $r=-0.558, p=0.031)$ subdomains. When the outlier in the MPS III group was removed, significantly lower scores were reported for both gross motor skills $(p=0.018)$ and fine motor skills $(p=0.030)$. All age-equivalent scores for children with MPS III fell below 18 months.

ECBI behaviour intensity and problem scores were significantly lower for children with MPS III than ID (Table 5), 
Table 4 VABS Subdomain scores (10-15 year olds)

\begin{tabular}{|c|c|c|c|c|c|c|}
\hline Domain & Subdomain & $\begin{array}{l}\text { Median MPS III score } \\
\text { median ( } N \text {, range) }\end{array}$ & $\begin{array}{l}\text { MPS III age equivalent } \\
\text { (years: months) }\end{array}$ & $\begin{array}{l}\text { Median ID score } \\
\text { median }(N \text {, range) }\end{array}$ & $\begin{array}{l}\text { ID age equivalent } \\
\text { (years: months) }\end{array}$ & $p$ value \\
\hline \multirow[t]{3}{*}{ Communication } & Receptive & $10.5(8,3-33)$ & $0: 11$ & $21(7,8-28)$ & $1: 9$ & 0.223 \\
\hline & Expressive & $16(8,2-90)$ & $0: 9$ & $61(7,9-73)$ & $2: 10$ & 0.165 \\
\hline & Written & $0(8,0-21)$ & $\leq 1: 10$ & $10(7,0-41)$ & $4: 6$ & 0.041 \\
\hline \multirow[t]{3}{*}{ Daily living skills } & Personal & $11(8,0-58)$ & $1: 1$ & $40(7,14-52)$ & $2: 11$ & 0.032 \\
\hline & Domestic & $0(8,0-8)$ & $\leq 0: 7$ & $13(7,1-22)$ & $4: 11$ & 0.002 \\
\hline & Community & $1(8,0-24)$ & $0: 3$ & $22(7,3-23)$ & $4: 10$ & 0.022 \\
\hline \multirow[t]{3}{*}{ Socialisation } & Interpersonal relationships & $23(8,11-47)$ & $0: 9$ & $23(7,8-42)$ & $0: 9$ & 0.449 \\
\hline & Play and leisure & $12(8,2-32)$ & $1: 1$ & $14(6,8-36)$ & $1: 3$ & 0.172 \\
\hline & Coping skills & $3.5(8,0-29)$ & $0: 7$ & $10(7,6-17)$ & $2: 1$ & 0.031 \\
\hline \multirow[t]{2}{*}{ Motor skills } & Gross & $12(7,3-79)$ & $0: 7$ & $47(7,4-67)$ & $1: 8$ & 0.096 \\
\hline & Fine & $16.5(8,1-54)$ & $1: 3$ & $34(7,12-64)$ & $3: 0$ & 0.093 \\
\hline
\end{tabular}

with large effect sizes, $(U=9, z=-2.199, r=-0.568$, $p=0.028)$ and $(U=6.5, z=-2.086, r=-0.578, p=0.037)$, respectively. The behaviour intensity score for children with ID exceeded clinical threshold (131) for problem behaviour while the MPS III score does not. The MPS III group had significantly lower scores on the irritability domain $(U=12.5, z=-2.025, r=-0.506, p=0.043)$ and on the current understanding $(U=11, z=-2.345, r=-0.569$, $p=0.019)$ and current expression subdomains $(U=6$, $z=-2.848, r=-0.691, p=0.004)$ of the SBRS. Of the MPS III group, 90\% were reported to have shown better comprehension and expressive communication skills in the past, compared to $28.5 \%$ of the ID group. Of the children with MPS III, 60\% had sleep problems (40\% severely disrupted), $90 \%$ were no longer continent, $10 \%$ had behavioural problems or over-activity, 50\% no longer walked and $60 \%$ were unresponsive most of the time.

\section{Discussion}

In the 2-9-year age range, gross motor skills were the only adaptive skills that differentiated between the MPS III and ID groups. In the 10-15-year age group, the ID group showed significantly more advanced adaptive skills than the MPS III group in all areas of daily living skills, written communication and coping skills and in current understanding and current expression. Thus, level of disability increased with age in the MPS III group, while the ID group acquired new skills with age, possibly accounting for the age-related decrease in challenging behaviour in MPS III as they lose physical and cognitive skills and are less able to actually perform such behaviour. Although such behavioural problems are a feature of the middle phase of MPS III, the high frequency is not in itself phenotypic and may be associated with ID level. Middle phase children with MPS III displayed significantly more behaviours relating to hyperactivity, orality, body movements, interactions with objects and inattention than the control group, but given the poor internal consistency of the interactions with objects domain on the SBRS, this finding should be viewed with caution. Such behaviours may be part of the behavioural phenotype of the middle phase of MPS III, but this requires further investigation [36,37]. In the late phase MPS III group, few behaviours remained problematic; possibly, parents were used to managing higher levels of challenging behaviour in the middle phase and/or because the reduction in challenging behaviour corresponded to the inevitable physical and cognitive deterioration-one parent remarked that they wished their child was still able to display challenging behaviour.

The present findings confirm previous reports of behaviours relating to orality, unusual affect and hyperactivity in the middle phase of MPS III and add that they occur significantly more frequently compared to matched controls. A novel finding was of unusual body movements being phenotypic in the middle stage of MPS III. The previously reported high rates of challenging behaviour and physical aggression in MPS III were found to be no different from matched controls in the middle phase and are probably associated with the level of ID. Interestingly, although unusual/inappropriate affect were no more frequent compared to matched controls, they were displayed by children with MPS III throughout their lives and even after other behaviours had disappeared. Unlike previous research, this study did not examine 'temper tantrums' as these are poorly defined and subjective in report. This study found sleep disturbance to be a common problem in MPS III but with lower prevalence than previous studies, which with a parallel of sleep in MPS III that identified that the quantity of night-time sleep in children with MPS III was not significantly different from typically developing children [23]. 
Table 5 Behaviour-related domain scores (10-15 year olds)

\begin{tabular}{|c|c|c|c|}
\hline & $\begin{array}{l}\text { MPS III median } \\
(N, \text { range })\end{array}$ & $\begin{array}{l}\text { ID median } \\
(N, \text { range })\end{array}$ & $p$ value \\
\hline \multicolumn{4}{|l|}{ ECBI } \\
\hline Intensity score & $76(8,36-174)$ & $155(7,74-201)$ & 0.028 \\
\hline Problem score & $1(7,0-21)$ & $14.5(6,1-29)$ & 0.037 \\
\hline \multicolumn{4}{|l|}{$A B C$} \\
\hline Irritability & $2(9,0-24)$ & $23(7,1-40)$ & 0.043 \\
\hline Lethargy & $7(9,2-28)$ & $7(7,4-27)$ & 0.915 \\
\hline Stereotypy & $2(9,0-14)$ & $5(7,8)$ & 0.183 \\
\hline Hyperactivity & $7(9,2-28)$ & $23(7,1-41)$ & 0.152 \\
\hline Inappropriate speech & $0(9,0-5)$ & $4(7,0-12)$ & 0.054 \\
\hline $\mathrm{ABC}$ total score & $26(9,6-80)$ & $54(7,11-106)$ & 0.081 \\
\hline \multicolumn{4}{|l|}{ SBRS } \\
\hline Current understanding & $10(10,2-38)$ & $33(7,14-41)$ & 0.019 \\
\hline Past understanding & $28(9,16-42)$ & $42(2,4-20)$ & 0.056 \\
\hline Current expression & $2(10,0-12)$ & $11(7,5-23)$ & 0.004 \\
\hline Past expression & $12(9,6-24)$ & $12(2,4-20)$ & 0.813 \\
\hline Orality & $20(10,2-36)$ & $15(7,0-26)$ & 0.243 \\
\hline Body movements & $10(10,4-30)$ & $10(7,0-23)$ & 0.590 \\
\hline Interactions with objects & $11(10,3-19)$ & $8(7,0-15)$ & 0.240 \\
\hline Activity and routines & $14(10,4-30)$ & $20(7,6-26)$ & 0.845 \\
\hline Emotional function & $6(10,0-13)$ & $5(7,2-14)$ & 0.883 \\
\hline Safety consciousness & $12(10,0-18)$ & $8(7,3-14)$ & 0.352 \\
\hline Fearfulness & $28(10,12-35)$ & $16(7,8-36)$ & 0.405 \\
\hline Social interaction & $13.5(10,2-22)$ & $17(7,8-25)$ & 0.282 \\
\hline Eye contact & $3(10,0-8)$ & $6(7,0-10)$ & 0.258 \\
\hline Emotional engagement & $7.5(10,4-14)$ & $6(7,2-13)$ & 0.257 \\
\hline Comfort seeking & $10(10,8-14)$ & $11(7,0-20)$ & 0.428 \\
\hline Attention & $12(10,6-18)$ & $11(7,3-18)$ & 0.883 \\
\hline Self-control/compliance & $6(10,0-16)$ & $10(7,4-18)$ & 0.281 \\
\hline Mood, anger and aggression & $5.5(10,0-42)$ & $19(7,2-33)$ & 0.117 \\
\hline Self-gratification & $0(10,0-2)$ & $2(7,0-5)$ & 0.217 \\
\hline
\end{tabular}

This study was limited by the small sample size and grouping of MPS III subtypes. It is possible that the within-group variability found in this study could be accounted for by genetic subtype. As MPS III subtypes are genetically distinct, the findings of this study can only be described as preliminary and identify areas to focus future research. A larger sample size would also show fewer outliers, as was the case in the late phase MPS III sample where there was an outlier in terms of ability, although this did not substantially affect the findings, and it is likely that this was a case of the MPS III B mild phenotype and thus indicative of the heterogeneous presentation of MPS III [15,14].

The SBRS is a relatively under-developed measure that requires further work to improve its psychometric properties, and therefore, the data derived from the SBRS should be treated with caution.

\section{Clinical implications}

The present findings indicate that families with children with MPS III may benefit from a different type of support service, in addition to their medical treatment, in the middle phase compared to the late phase of the disorder. In the middle phase, needs associated with hyperactivity and behavioural concerns could be met by community learning disability services, while issues relating to deterioration and loss of skills and end-of-life care in the late phase may be best met by paediatric psychology services, although the heterogeneity in individual presentation means the age at which these needs change will vary. In the middle phase, the behavioural problems related to inattention and hyperactivity may benefit from the same type of behavioural interventions as children of a similar developmental level diagnosed with Attention Deficit Hyperactivity Disorder (ADHD). Additionally, a parallel study found that parents of children with MPS III experience similar levels of stress to those with a child with ID [23]. The National Institute for Clinical Excellence (NICE) guidelines recommend parenting groups as the primary intervention for children with ADHD and ID with subsequent individual parenting skills interventions if necessary [38]. As behavioural interventions are effective in MPS III [5], parenting interventions could be developed for parents of children with MPS III which could address both managing behavioural issues and coping with the progressive, terminal prognosis of MPS III.

\section{Conclusions}

Although this study was predicated on a biological basis for the behaviour of children with MPS III, the complex relationship between environment, biology, learning and personal factors must be considered given that social context [39], physical environment and triggers [40] and effect of personal characteristics on phenotypic behaviour [41] are demonstrably important when examining behaviour in other genetic syndromes. Examination of differences in behavioural presentation between the genetic subtypes of MPS III would also inform the understanding of the genotype-phenotype relationship in MPS III, but this may be difficult within a UK sample and might require international recruitment, possibly utilising on-line data collection.

No single questionnaire in this study captured the behavioural phenotype or was completed by parents exactly according to guidelines, and the present findings should inform further development of existing and novel questionnaire-based measures for use with this small but important population $[9,10]$. Moreover, given the 
progressive nature of MPS III coupled with the evident phenotypic heterogeneity, future research could use more naturalistic methodologies with an emphasis on describing the progressive nature of the disorder rather than on mapping evident differences.

\section{Competing interests}

The authors declare they have no competing interests.

\section{Authors' contributions}

Conceived and designed the experiments: EMC, LVM, ML, SG, DJH, JEW and SJ. Performed the experiments: EMC and SG. Analysed the data: EMC. Wrote the paper: EMC and DJH. Recruited participants: EMC, SG, LVM, ML, JEW and SJ. Data entry: EMC. Edited the manuscript: DJH, BWB and EMC. All authors read and approved the final manuscript

\section{Acknowledgments}

The authors would like to thank the families of the children with MPS who participated in this study and to dedicate this paper to the memory of Prof Ed Wraith who was closely involved with this research but who sadly died in 2013.

\section{Funding}

This work was funded by a programme grant awarded to BWB by the UK Mucopolysaccharidosis Society and the Norah Al Ballah Foundation. Additional funds were provided by the University of Manchester.

\section{Author details}

'Section for Clinical and Health Psychology, School of Psychological Sciences, University of Manchester, Zochonis Building, Brunswick Street, Manchester M13 9PL, UK. ²Department of Genetic Medicine, St Mary's Hospital, Manchester, UK. ${ }^{3}$ Stem Cell \& Neurotherapies, Faculty of Medical and Human Sciences, University of Manchester, Manchester, UK.

Received: 13 October 2013 Accepted: 10 December 2014 Published: 31 December 2014

\section{References}

1. Applegarth DA, Toone JR, Lowry RB: Incidence of inborn errors of metabolism in British Columbia, 1969-1996. Pediatrics 2000, 105(1):e10

2. Malm G, Mansson J: Mucopolysaccharidosis type III (Sanfilippo disease) in Sweden: clinical presentation of 22 children diagnosed during a 30-year period. Acta Paediatr 2010, 99(8):1253-1257.

3. Wegrzyn G, Jakóbkiewicz-Banecka J, Narajczyk M, Wisniewski A, Piotrowska E, GabigCiminska M, Wegrzyn A: Why are behaviors of children suffering from various neuronopathic types of mucopolysaccharidoses different? Med Hypotheses 2010, 75(6):605-609.

4. Cleary M, Wraith J: Management of mucopolysaccharidosis type III. Arch Dis Child 1993, 69(3):403-406.

5. Fraser J, Gason A, Wraith J, Delatycki M: Sleep disturbance in Sanfilippo syndrome: a parental questionnaire study. Arch Dis Child 2005, 90(12):1239-1242.

6. Valstar MJ, Marchal JP, Grootehhuis M, Colland V, Wijburg FA: Cognitive development in patients with mucopolysaccharidosis type III (Sanfilippo syndrome). Orphanet J Rare Dis 2011, 6:43.

7. Meyer A, Kossow K, Gal A, Muhlhausen C, Ullrich K, Braulke T, Muschol N: Scoring evaluation of the natural course of mucopolysaccharidosis type IIIA (Sanfilippo syndrome type A). Pediatrics 2007, 120(5):e1255-e1261.

8. Ruijter GJG, Valstar MJ, van de Kamp JM, van der Helm RM, Durand S, van Diggelen OP, Wijburg FA: Clinical and genetic spectrum of Sanfilippo type C (MPS IIIC) disease in The Netherlands. Mol Genet Metab 2007, 93(2):104-111.

9. Malcolm C, Forbat L, Anderson G, Gibson F, Hain R: Challenging symptom profiles of life-limiting conditions in children: a survey of care professionals and families. Palliat Med 2011, 25(4):357-364.

10. Bax MC, Colville GA: Behaviour in mucopolysaccharide disorders. Arch Dis Child $1995,73(1): 77-81$

11. Valstar M, Ruijter GJG, Van Diggelen O, Poorthuis B, Wijburg F: Sanfilippo syndrome: a mini-review. J Inherit Metab Dis 2008, 31(2):240-252.
12. Cross E, Hare DJ: Behavioural phenotypes of the mucopolysaccharide disorders: a systematic literature review of cognitive, motor, social, linguistic and behavioural presentation in the MPS disorders. $J$ Inherit Metab Dis 2013, 36:189-200

13. Héron B, Mikaeloff Y, Froissart R, Caridade G, Maire I, Caillaud C, Levade T, Chabrol B, Feillet F, Ogier H, Valayannopoulos V, Michelakakis H, Zafeiriou D, Lavery L, Wraith E, Danos O, Heard J-M, Tardieu M: Incidence and natural history of mucopolysaccharidosis type III in France and comparison with United Kingdom and Greece. Am J Med Genet 2010, 155A(1):58-68.

14. Valstar MJ, Neijs S, Bruggenwirth HT, Olmer R, Ruijter GJG, Wevers RA, van Diggelen OP, Poorthuis BJ, Halley DJ, Wijburg FA: Mucopolysaccharidosis type IIIA: clinical spectrum and genotype-phenotype correlations. Am Neurol Assoc 2010, 68:876-887.

15. Van de Kamp JJP, Niermeijer MF, Von Figura K, Giesberts MAH: Genetic heterogeneity and clinical variability in the Sanfilippo syndrome (types A, B, and C). Clin Genet 1981, 20:152-160.

16. Nidiffer $F$, Kelly $T$ : Developmental and degenerative patterns associated with cognitive, behavioural and motor difficulties in the Sanfilippo syndrome: an epidemiological study. J Ment Defic Res 1983, 27(3):185-203.

17. Van Schrojenstein-de Valk HM, van de Kamp JJ: Follow-up on seven adult patients with mild Sanfilippo B-disease. Am J Med Genet 1987, 28(1):125-129.

18. Colville GA, Watters JP, Yule W, Bax M: Sleep problems in children with Sanfilippo syndrome. Dev Med Child Neurol 1996, 38:538-544.

19. Moog U, van Mierlo I, van Schrojenstein Lantman-de Valk HMJ, Spaapen L, Maaskant MA, Curfs LMG: Is Sanfilippo type B in your mind when you see adults with mental retardation and behavioral problems? Am J Med Genet 2007, 145C(3):293-301.

20. Valstar MJ, Bruggenwirth HT, Olmer R, Wevers RA, Verheijen FW, Poorthuis BJ, Wijburg FA: Mucopolysaccharidosis type IIIB may predominantly present with an attenuated clinical phenotype. $J$ Inherit Metab Dis 2010, 33(6):759-767.

21. Mariotti P, Della Marca G, Luvone L, Vernacotola S, Ricci R, Mennuni GF, Mazza S: Sleep disorders in Sanfilippo syndrome: a polygraphic study. Clin Electroencephalogr 2003, 34(1):18-22.

22. Mahon L, Lomax M, Grant S, Cross E, Jones S, Wraith E, Bigger B, Canal M, Hare DJ: Actigraphic assessment of sleep in children with mucopolysaccharidosis Type III. PLoS One 2014, 9(2):1-7.

23. Grant S, Cross E, Jones S, Wraith E, Bigger B, Hare DJ: Parental stress, coping, resilience, anxiety, depression, and social support in parents with a child with Mucopolysaccharidosis Type III (MPS III, Sanfilippo syndrome) and parents of children with intellectual disabilities (I.D.). J Inherit Metab Dis 2013, 36:281-291.

24. Pendaries C: Pilot study on the development of the learning disability Healthcare Resource Groups. Br J Learn Disabil 1997, 25(3):122-126.

25. Kushlick A, Blunden R, Cox GR: A method of rating behaviour characteristics for use in large scale surveys of mental handicap. Psychol Med 1973, 3(4):446-478.

26. Sparrow SS, Cicchetti VD, Balla AD: Vineland Adaptive Behavior Scales. 2nd edition. Circle Pines, MN: American Guidance Service; 2005.

27. Aman MG, Singh NN, Stewart AW, Field CJ: The Aberrant Behavior Checklist: a behavior rating scale for the assessment of treatment effects. Am J Ment Defic 1985, 89(5):485-491.

28. Aman MG, Burrow W, Wolford PL: The Aberrant Behavior ChecklistCommunity: factor validity and effect of subject variables for adults in group homes. Am J Ment Retard 1995, 100(3):283-292.

29. Newton J, Sturmey P: The Aberrant Behaviour Checklist: a British replication and extension of its psychometric properties. I Intellect Disabil Res 1988, 32(2):87-92.

30. Eyberg S, Pincus D: Eyberg Child Behavior Inventory (ECBI). Odessa FL: Psychological Assessment Resources; 1999.

31. Eyberg SM, Ross AW: Assessment of child behavior problems: the validation of a new inventory. J Clin Child Adolesc Psychol 1978, 7(2):113-116.

32. Burns GL, Patterson DR: Conduct problem behaviors in a stratified random sample of children and adolescents: new standardization data on the Eyberg Child Behavior Inventory. Psychol Assess: I Consult Clin Psychol 1990, 2(4):391.

33. Shapiro E: Personal Correspondence: University of Minnesota; 2010. 
34. Nakagawa S: A farewell to Bonferroni: the problems of low statistical power and publication bias. Behav Ecol 2004, 15:1044-1045.

35. Rosenthal R: Meta-analytic procedures for social research. 2nd edition. Newbury Park, CA: Sage; 1991.

36. Potegal M, Yund B, Rudser K, Ahmed A, Delaney K, Nestrasil I, Whitley CB, Shapiro EG: Mucopolysaccharidosis Type IIIA presents as a variant of Klüver-Bucy syndrome. J Clin Exp Neuropsychol 2013, 35(6):608-614.

37. Rumsey RK, Rudser K, Delaney K, Potegal M, Whitley CB, Shapiro EG: Acquired autistic behaviors in children with mucopolysaccharidosis type IIIA. J Pediatrics 2014, 164(5):1147-1151. e1.

38. National Institute for Health and Clinical Excellence: Attention Deficit Hyperactivity Disorder (ADHD). CG72. London: NICE; 2008.

39. Oliver C: Self-injurious behaviour in children with learning disabilities: recent advances in assessment and intervention. J Child Psychol Psychiatry 1995, 36:909-927.

40. Hanley GP, Iwata BA, McCord BE: Functional analysis of problem behaviour a review. J Appl Behav Anal 2003, 36:147-185.

41. McClintock K, Hall S, Oliver C: Risk markers associated with challenging behaviours in people with intellectual disabilities: a meta-analytic study. J Intellect Disabil Res 2003, 47:405-416.

doi:10.1186/1866-1955-6-46

Cite this article as: Cross et al:: An investigation of the middle

and late behavioural phenotypes of Mucopolysaccharidosis Type-III. Journal of

Neurodevelopmental Disorders 2014 6:46.

\section{Submit your next manuscript to BioMed Central and take full advantage of:}

- Convenient online submission

- Thorough peer review

- No space constraints or color figure charges

- Immediate publication on acceptance

- Inclusion in PubMed, CAS, Scopus and Google Scholar

- Research which is freely available for redistribution 